\title{
The C-X-C signalling system in the rodent vs primate testis: impact on germ cell niche interaction
}

\author{
Laura Heckmann, Tim Pock, Ina Tröndle and Nina Neuhaus \\ Centre of Reproductive Medicine and Andrology, Institute of Reproductive and Regenerative Biology, \\ Münster, Germany \\ Correspondence should be addressed to N Neuhaus; Email: nina.neuhaus@ukmuenster.de
}

\begin{abstract}
In zebrafish, action of the chemokine Cxcl12 is mediated through its G-protein-coupled seven-transmembrane domain receptor Cxcr4 and the atypical receptor Cxcr7. Employing this animal model, it was revealed that this Cxcl12 signalling system plays a crucial role for directed migration of primordial germ cells (PGC) during early testicular development. Importantly, subsequent studies indicated that this regulatory mechanism is evolutionarily conserved also in mice. What is more, the functional role of the CXCL12 system does not seem to be limited to early phases of testicular development. Data from mouse studies rather demonstrate that CXCL12 and its receptors are also involved in the homing process of gonocytes into their niches at the basal membrane of the seminiferous tubules. Intriguingly, even the spermatogonial stem cells (SSCs) present in the adult mouse testis appear to maintain the ability to migrate towards a CXCL12 gradient as demonstrated by functional in vitro migration assays and in vivo germ cell transplantation assays. These findings not only indicate a role of the CXCL12 system throughout male germ cell development in mice but also suggest that this system may be evolutionarily conserved. In this review, we take into account the available literature focusing on the localization patterns of the CXCL12 system not only in rodents but also in primates, including the human. Based on these data, we discuss whether the CXCL12 system is also conserved between rodents and primates and discuss the known and potential functional consequences.

Reproduction (2018) 155 R211-R219
\end{abstract}

\section{Introduction}

The ability of cell migration is a key feature of early germ cells. Following specification at extraembryonic locations, germ cells need to move to the target sites of the developing gonads. Employing zebrafish as animal model, the interaction of the chemokine Cxcl12 with its receptors Cxcr4 and Cxcr7 was shown to be decisive for the directionality of primordial germ cell (PGC) migration (Richardson \& Lehmann 2010). Specifically, isoform Cxcl12a is expressed by somatic cells and acts through the $\mathrm{G}$ protein-coupled receptor $\mathrm{Cxcr} 4 \mathrm{~b}$ localized to the cell surface of PGCs and induces migration (Doitsidou et al. 2002). In addition, Cxcl12a also acts through the alternative receptor $\mathrm{Cxcr} 7$, which is expressed throughout somatic tissues. However, in contrast to Cxcr4 binding to $\mathrm{Cxcr} 7$ rather results in internalization of the chemokine and as a consequence of this in formation of a Cxcl12a gradient (Doitsidou et al. 2002, Knaut et al. 2003, Boldajipour et al. 2008, Mahabaleshwar et al. 2008, Raz \& Mahabaleshwar 2009, Zohni et al. 2012, Bussmann \& Raz 2015). First insights regarding these early processes of PGC migration have been gained employing the zebrafish, exploiting the fast extrauterine development of embryos as well as the transparency, which facilitates in vivo analyses of selected strains (Doitsidou et al. 2002, Bussmann \& Raz 2015). Later studies revealed that the CXCL12/CXCR4 interaction is also crucial for directed PGC migration in the mouse (Molyneaux et al. 2003). For unveiling the role of this chemokine system for subsequent stages of germ cell development in mice, it was a clear advantage that protocols for the isolation of spermatogonial stem cells (SSCs) as well as the germ cell transplantation assay are established, facilitating functional migration studies in vitro and in vivo. Following PGC migration, the next stage requiring germ cell migration is the migration of gonocytes (also referred to as prospermatogonia) from the centre of the seminiferous tubules towards the basal lamina and into their stem cell niches. In mice, this process again is mediated by the interaction of CXCL12 and CXCR4 (Payne et al. 2010, Gallagher et al. 2013), indicating that this regulatory mechanism remains active beyond the phase of germ cell migration towards the gonads. In the adult testis, the ability of germ cell migration may not be obviously required in tissue homeostasis. Yet, the repopulation of seminiferous tubules following gonadotoxic insult and depletion of spermatogonia involves the migration of remaining spermatogonia prior to homing into vacated niches. It 
can be postulated that the CXCL12 system remains a constitutive part of the germ cell niche throughout all stages of germ cell development or is reactivated in these cases of gonadotoxic insult. The purpose of this review is to discuss the functional roles of the CXCL12 system throughout germ cell development focusing on data obtained in rodents and primates.

\section{General characteristics and function of CXCL12 and its receptors CXCR4 and CXCR7}

Chemotactic cytokines, so-called chemokines, are small proteins $(8-14 \mathrm{kDa})$ that regulate the migration of cells. Their action is mediated via binding to distinct G-proteincoupled seven-transmembrane (7TM) domain receptors (de Vries et al. 2006, Zlotnik et al. 2006). Chemokines are grouped into inflammatory and homeostatic chemokines. Homeostatic chemokines are constitutively expressed and involved in various developmental processes. Amongst the homeostatic chemokines the CXCL12 (chemokine (C-X-C motif) ligand 12)/CXCR4 (chemokine (C-X-C motif) receptor 4) system is essential for the development of the heart, brain and large vessels during mouse embryo development (Ma et al. 1998, Zou et al. 1998). In addition to CXCR4, CXCL12 can also bind to the atypical chemokine receptor CXCR7 (Balabanian et al. 2005, Burns et al. 2006). Binding affinity of CXCL12 to this atypical receptor is even 10x higher compared to CXCR4 (Burns et al. 2006). Structurally, receptors belonging to the group of atypical chemokine receptors also have the classical 7-transmembrane structure that is typical of G protein-coupled chemokine receptors, however, due to a modified motive, binding of the chemokine does not induce classical signalling response. Nonetheless, significance of CXCR7 function for embryo development was demonstrated by the lethal phenotype of CXCR7knockout mice. Importantly, though, these knockout mice die due to cardiovascular defects, a phenotype different from defects observed in CXCL12- or CXCR4-knockout mice (Sierro et al. 2007, Gerrits et al. 2008).

\section{Functional role of the CXCL12 system for the migration of PGCs and colonization of the gonads}

Primordial germ cells (PGCs) are specified early during mammalian embryonic development. They can first be identified at the embryonic yolk sac from where they migrate via the hindgut to the gonadal ridge (Aeckerle et al. 2012, 2015, Saitou \& Yamaji 2012, de Felici 2013, Tang et al. 2015, 2016). PGCs increase in number during the process of migration and maintain their proliferative activity during subsequent colonization of the genital ridges. The general steps of germ cell specification and migration but not the timing of these processes are comparable in mammals (Table 1).

Insights regarding the role of the $\mathrm{Cxcl} 12$ system for the process of germ cell migration have been gained in zebrafish. Benefit of this animal model was that early developmental stages are almost transparent enabling the identification and tracking of PGCs in life animals. In this animal model, specification of germ cells occurs at four different positions and germ cells subsequently migrate mediated through the Cxcl12/Cxcr4/Cxcr7 system to the sites of the developing genital ridge (Doitsidou et al. 2002, Raz 2004). Loss of the chemokine or its receptor in zebrafish resulted in PGCs showing a random rather than a directed migration pattern (Raz 2004, Richardson \& Lehmann 2010, Wei \& Liu 2014). High conservation of Cxcl12 amino acid sequence between zebrafish and mice rendered a conserved function of this chemokine likely (Doitsidou et al. 2002).

To determine the functional role of CXCL12/CXCR4 interaction during the process of mouse PGC migration, CXCR4-mutant mice were compared to age-matched controls. Until day E9.5 germ cell development progressed normally demonstrating that the interaction of CXCL12/CXCR4 is not required for germ cell specification or for initial migration (Molyneaux et al. 2003). Of note, this is different from findings in the zebrafish as mutations as well as oligo-mediated loss of functions resulted in an impaired migration from the start (Doitsidou et al 2002, Knaut et al. 2003). In the mouse though, CXCL12 promoted directed migration of PGCs and in particular the homing process of PGCs into the gonads.

Whether the CXCL12 system is also directing human PGC migration remains hitherto unknown, but data gained from cell line experiments, suggest that this may indeed be the case. Two studies employed TCam-2 cells, a human testicular germ cell tumour-derived cell line (Gilbert et al. 2010, Mclver et al. 2013), which share key characteristics with PGCs also regarding their gene

Table 1 Chronology of important events during prenatal development of mice, marmosets and humans.

\begin{tabular}{|c|c|c|c|c|}
\hline \multirow[b]{2}{*}{ Event } & \multicolumn{3}{|c|}{ Age } & \multirow[b]{2}{*}{ References } \\
\hline & Mouse & Marmoset & Human & \\
\hline PGC commitment and specification (epiblast) & E6.25-6.5 & Unknown & E12-16 & Saitou \& Yanaji (2012), Tang et al. (2015) \\
\hline Identification of PGCs at the yolk sac & E7.5-8 & E50 & E21-28 & $\begin{array}{l}\text { Saitou \& Yanaji (2012), De Felici (2013), Tang et al. (2015), } \\
\text { Aeckerle et al (2015) }\end{array}$ \\
\hline Localization of PGCs at the genital ridge & E10.5-11.5 & E65-75 & E35-42 & $\begin{array}{l}\text { Saitou \& Yanaji (2012), De Felici (2013), Tang et al. (2015), } \\
\text { Aeckerle et al. (2015) }\end{array}$ \\
\hline Differentiation of gonadal anlage into testes & E12 & E75 & E42 & $\begin{array}{l}\text { Li et al. (2005), Saitou \& Yanaji (2012), De Felici (2013), } \\
\text { Tang et al. (2015) }\end{array}$ \\
\hline
\end{tabular}


expression profile (Irie et al. 2015). Particularly, TCam-2 cells show expression of CXCR4 as well as CXCR7 (Gilbert et al. 2010). Expression of these cell surface receptors was of functional relevance as demonstrated by migration assays using a Boyden chamber approach with medium supplemented with CXCL12 (Mclver: 50, 100, $200 \mathrm{ng} / \mathrm{mL}$; Gilbert: $100 \mathrm{ng} / \mathrm{mL}$ ) in the lower chamber. Compared to a no-gradient control the ratio of migrating cells increased significantly in response to CXCL12. Interestingly, adding the CXCR4-specific antagonist AMD3100 (Mclver: 25 nM; Gilbert: $2.5 \mathrm{ng} /$ $\mathrm{mL}$ ) to the lower chamber or applying a CXCR4-specific knockdown reduced the number of migrating cells significantly in comparison to the no-gradient control despite the presence of a CXCL12 gradient (Gilbert et al. 2010, Mclver et al. 2013). Conclusively, the influence of the CXCL12/CXCR4 axis on the migration of TCam-2 cells provides a first indication that the chemokine and its receptor may also play a role in migration of human PGCs.

\section{The spermatogonial stem cell niche and the role of the CXCL12 system}

Following PGC migration into the developing gonads, germ cells colonize the genital ridges. Early male germ cells, which are now located within the seminiferous tubules of the gonad are referred to as gonocytes. In mice, gonocytes enter a mitotically quiescent phase and shortly after birth resume proliferation and migrate from the center of the cords to the basement membrane and give rise to the spermatogonial population including the spermatogonial stem cells (SSC) (Nagano et al. 2000, Drumond et al. 2011, Saitou \& Yamaji 2012). In primates, fetal germ cells proliferate throughout gestation and germ cell proliferation continues until the first weeks after birth (Honecker et al. 2004, Mitchell et al. 2008). Comparable to rodents, gonocytes in primate testicular tissues migrate to the basement membrane and differentiate into spermatogonia after birth. However, this process spans a longer period in humans as well as in marmoset monkeys (Huff et al. 2001, Li et al. 2005, Mitchell et al. 2008).

After entering the gonadal ridge, germ cells home into their testicular stem cell niches at the basement membrane of seminiferous tubules early during development. These niches are microenvironments composed of cellular as well as molecular components, which regulate SSC self-renewal as well as the differentiation into haploid spermatozoa (van der Kooy et al. 2000, Spradling et al. 2001). Importantly though, differences in the SSC systems in rodents and men make the existence of different niche types likely. Characteristic of the SSC system in mice is that the $A_{\text {single }}$ spermatogonia, which include the stem cell population, give rise to large cell clones via numerous mitotic divisions (Ehmcke et al. 2006).
In contrast to that, the adult SSC system in primates contains $A_{\text {dark }}$ spermatogonia, which are considered the mitotically quiescent reserve, a cell population which does not exist in the rodent system. Additionally, the SSC system in primates contains the $A_{\text {pale }}$ spermatogonia, which actively proliferate thereby preserving the stem cell pool or give rise to B spermatogonia (Ehmcke et al. 2006). In mice, functional role of individual growth factors have been demonstrated for regulation of SSC self-renewal and maintenance (Meng et al. 2000, Chen \& Liu 2015). Even though, expression of individual growth factors or their respective receptors can be detected in mice as well as in men, different niches are required for support of respective SSC systems. In particular, Sertoli cells are an important component of the SSC niche, as they form the compartments within the seminiferous tubules and provide physical contact to germ cells at different stages of germ cell differentiation. Moreover, Sertoli cells provide essential growth factors including glial cell line-derived growth factor (Meng et al. 2000, Hofmann 2008), fibroblast growth factor 2 (Mullaney \& Skinner 1992, Goriely et al. 2003) and Ets variant 5 (ETV5) (Sette et al. 2000, Hess et al. 2006, O'Bryan et al. 2012). A number of studies have identified GDNF as a crucial factor regulating self-renewal and maintenance of SSCs (Meng et al. 2000). Finally, the transcription factor ETV5, which helps to retain stem cells within their niches, was demonstrated to regulate expression of chemokine genes including $\mathrm{CxC} / 12$ in somatic Sertoli cells (Yoon et al. 2009, Chen et al. 2015). The role of this chemokine and its contribution to the SSC niche will be outlined in the following.

\section{Expression pattern indicates a continuing role of the CXCL12 system throughout germ cell development}

A functional role of the CXCL12 system for directed migration of early germ cells has been demonstrated in zebrafish and mice. Prerequisite for a continuing role of the CXCL12 system throughout germ cell development is the expression of the chemokine and its receptors in the testis or the ability to reactivate their expression also at later developmental stages.

To assess whether CXCL12 is expressed in testicular tissues postnatally, transcript profiles were determined throughout postnatal development of mice (on days 1 , 7, 14, 21 and >37). Interestingly, Cxc/12 levels remained stable till day 21 and were highest in adult animals (>37 days). Expression was confirmed at the protein level and CXCL12 was specifically localized in the cytoplasm of Sertoli cells (Payne et al. 2010, Chen et al. 2015), the somatic cell type with the most direct interaction with the germ cell population.

What is more, transcripts of the receptors Cxcr4 and $\mathrm{CxCr} 7$ were also detected at RNA level throughout mouse testicular development. The expression profile 
was different from the chemokine, however, as relative expression levels of $\mathrm{CxCr} 4$ and $\mathrm{CxCr} 7$ continuously increased from day 1 onwards and reached highest levels in animals aged $>37$ and 21 days, respectively. Requirement for a CXCL12-induced effect on the germ cell population is the expression of respective receptors on the cell surface of spermatogonia. For CXCR4, relevant studies have demonstrated that spermatogonia isolated via the cell surface receptor THY1, display higher expression levels of CXCR4 compared to testicular somatic cells (Oatley et al. 2006, Niu et al. 2016). More importantly even, CXCR4 protein was localized to the cell surface of spermatogonia residing along the basement membrane in testicular tissues from 3 and 5 days old as well as adult mice (Payne et al. 2010, Westernströer et al. 2014, Chen et al. 2015, Niu et al. 2016). Upon induction of meiosis (days 14 and 21 pp), expression of CXCR4 was also detected in differentiating germ cells as well as in spermatids and even interstitial cells in adult testes. Slightly controversial results were only obtained in one study, which reported the expression of the protein in spermatogonia and also in the somatic Sertoli and interstitial cells of the adult testis (Yoon et al. 2009).

Surprising data were obtained regarding the localization of CXCR7 in mice. In zebrafish, this receptor is localized to somatic cells during PGC migration and rather functions as a decoy receptor for Cxcl12 (Boldajipour et al. 2008). This alternative receptor CXCR7 displays a germ-cell-specific expression pattern in mice with a specific expression in gonocytes (day $1 \mathrm{pp)}$ and spermatogonia at the basement membrane at subsequent developmental time points (days 7, 14 and $21 \mathrm{pp})$. Intriguingly though, co-stainings did neither lead to detection of cells co-expressing the spermatogonial marker LIN28a and CXCR4 nor CXCR7 and CXCR4 (Westernströer et al. 2014), indicating distinct populations of mouse spermatogonia with hitherto unknown properties.

Taken together, available literature demonstrates an evolutionarily and developmentally conserved expression profile of CXCL12 and its receptor CXCR4. This lends confidence to the assumption that the CXCL12 system remains functionally active even postnatally. However, the germ cell-specific expression pattern of CXCR7 suggests that the function of this receptor in mice may go beyond that of a decoy receptor.

To assess if this system is also conserved during testicular development in primates, localization studies have been performed employing the marmoset monkey as non-human primate model. This model has the advantage that it shares many similarities with the human, regarding its spermatogonial stem cell system as well as postnatal developmental phases (Albert et al. 2010). In marmosets, CXCL12 is constitutively expressed in the cytoplasm of Sertoli cells of infantile (8 and 16 wpp), prepubertal (32 wpp) and pubertal
(52 wpp) animals. Evidence for continued expression also in adult testis comes from marmoset, the macaque (Macaca fascicularis) as well as the human (Gilbert et al. 2010, Mclver et al. 2013, Westernströer et al. 2015, Tröndle et al. 2017). Data on the expression pattern of the receptor CXCR4, however, is less complete. While data are hitherto not available for marmoset monkey, in human testicular tissues, CXCR4 was detected in all germ cell stages, with the exception of mature sperm (Gilbert et al. 2010, Mclver et al. 2013). It is of note though that an independent study rather reported an expression of CXCR4 in interstitial leukocytes and macrophages of testicular tissues (Habasque et al. 2002). Reasons for this inconsistency remain hitherto elusive. Comprehensive and consistent data have been published though for the expression profile of the alternative receptor CXCR7. During postnatal testicular development of the marmoset (16, 32, 52 and >80 wpp) and human (2 weeks and 6 months) CXCR7 is expressed by a subset of gonocytes, pre-spermatogonia and spermatogonia. This expression pattern persisted as CXCR7 showed a specific expression in pre-meiotic cells located at the basement membrane in adult tissues (Westernströer et al. 2015).

Based on current data, the expression pattern of CXCL12 and its receptors appears to be highly conserved in mice and primates including men (Fig. 1). Current data demonstrate that expression of CXCL12 and its receptors is retained throughout testicular development, and it has been suggested that this system may also allow for directed germ cell migration in the adult testis. Although spermatogonia may not undergo extensive migration during tissue homeostasis, it is conceivable that gonadotoxic insults resulting in a depletion of spermatogonia necessitate migration of SSCs for the recolonization of seminiferous tubules and re-establishment of spermatogenesis. In this case, the CXCL12 system would act as a safeguard for male fertility. Prerequisite for this function are the persistent ability of adult SSCs to migrate towards CXCL12. To test this functional property, in vitro as well as in vivo migration assays have been performed using mice as animal models.

\section{CXCL12-induced migration of adult mouse germ cells/SSCs in vitro and in vivo}

First evidence that undifferentiated germ cells maintain their ability to respond to a CXCL12 gradient came from in vitro assays. The Boyden-chamber assay was employed as in vitro system and revealed that three times more mouse SSCs migrated in response to CXCL12 (10 ng/L) compared to controls. This effect was abolished by addition of AMD3100, a selective chemical antagonist of CXCR4. These in vitro data strongly suggested that directed migration also of adult murine SSCs is regulated in a CXCL12-dependent fashion (Niu et al. 2016). 


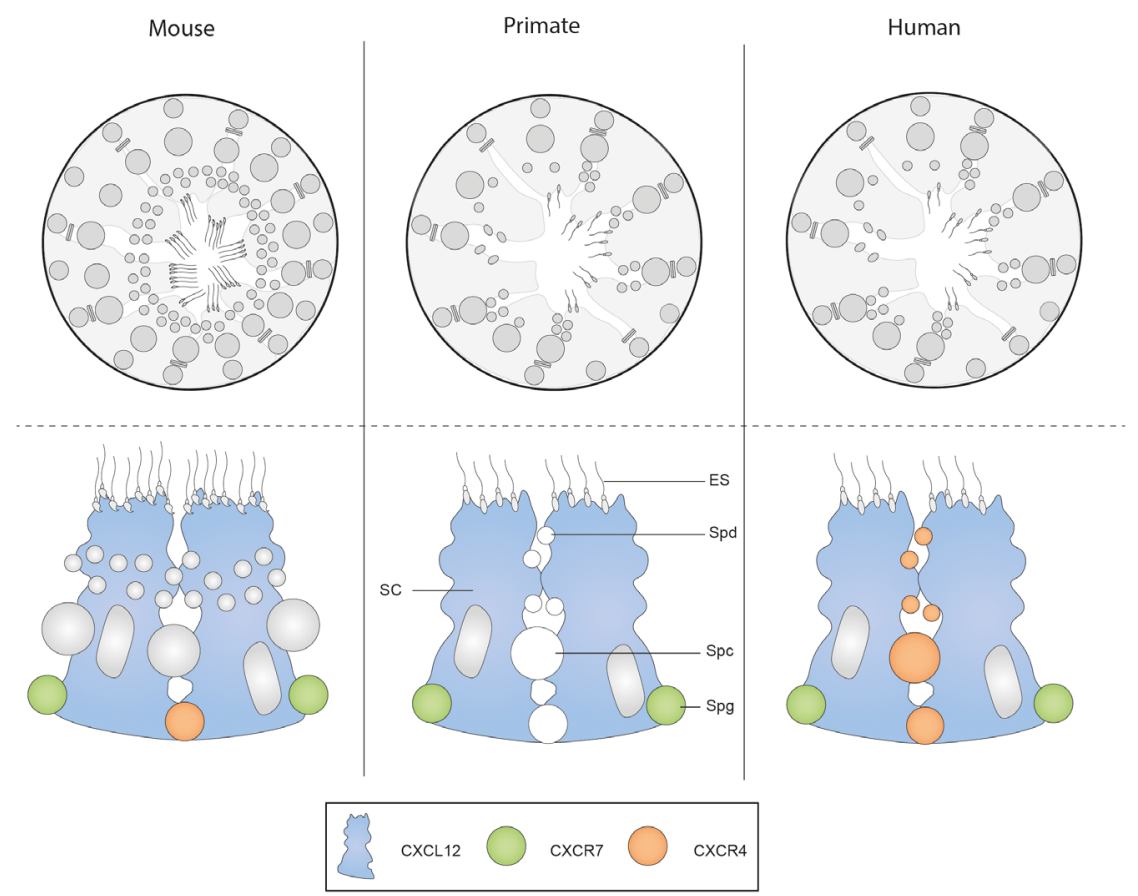

Figure 1 Localization of CXCL12, CXCR4 and CXCR7 in seminiferous tubules of mice, marmoset monkeys and humans. CXCL12 (blue) is expressed in the cytoplasm of Sertoli cells of all species. CXCR4 (orange) expression was detected in cells located at the membrane of seminiferous tubules in mice, whereas in human tissues, the receptor is expressed in all germ cells except for mature sperm. No data are available for the CXCR4 expression in marmoset testicular tissues. Expression of CXCR7 (green) was determined in spermatogonia in adult testes of all three species. ES, elongated spermatids; SC, Sertoli cells; Spc, spermatocytes; Spd, spermatids; Spg, spermatogonia.
To unravel the potential role of the CXCL12 system for SSC migration and homing in vivo, a modified germ cell transplantation assay has been employed. The original germ cell transplantation assay was established in 1994 and entails the transplantation of donor cells into seminiferous tubules, devoid of germ cells (Brinster \& Zimmermann 1994). Following transplantation, SSCs can migrate from the lumen of the seminiferous tubules towards the basement membrane, where they colonize empty niches and re-establish spermatogenesis (Nagano et al. 2000). This assay thereby provides functional proof for the presence of SSCs in a cell population. More recent studies have used modification of the SSC niches to unveil those factors that promote or prevent homing of SSCs into their niches. Whereas the artificially increased expression of rat GDNF prior to germ cell transplantation did not result in increased SSC colonization, increased CXCL12 expression led to a 2 -fold increase in SSC colonies (Kanatsu-Shinohara et al. 2012). These findings were corroborated by independent studies demonstrating that the transplantation with AMD3100 along with the germ cell suspension resulted in significantly lower numbers of donor-derived SSC colonies. A comparable effect was observed following repeated administration of AMD3100 following germ cell transplantation (Niu et al. 2016). These analyses demonstrated the specific role of CXCL12/CXCR4 interaction for SSC homing also in adult mouse testes and indicate a role of the CXCL12 system for tissue regeneration (Fig. 2). To date, no functional data are available for primates or the human, but it appears likely that the same mechanisms also apply in these species. As the CXCL12 concentration had been artificially increased in the outlined experiments, a natural increase of CXCL12 in the testis upon germ cell loss is required for this system to be of functional relevance.

\section{Response of niche-associated factors to gonadotoxicity in mice and primate testes}

Germ cell loss and associated emptying of SSC niches in mice can be induced by busulfan which exerts

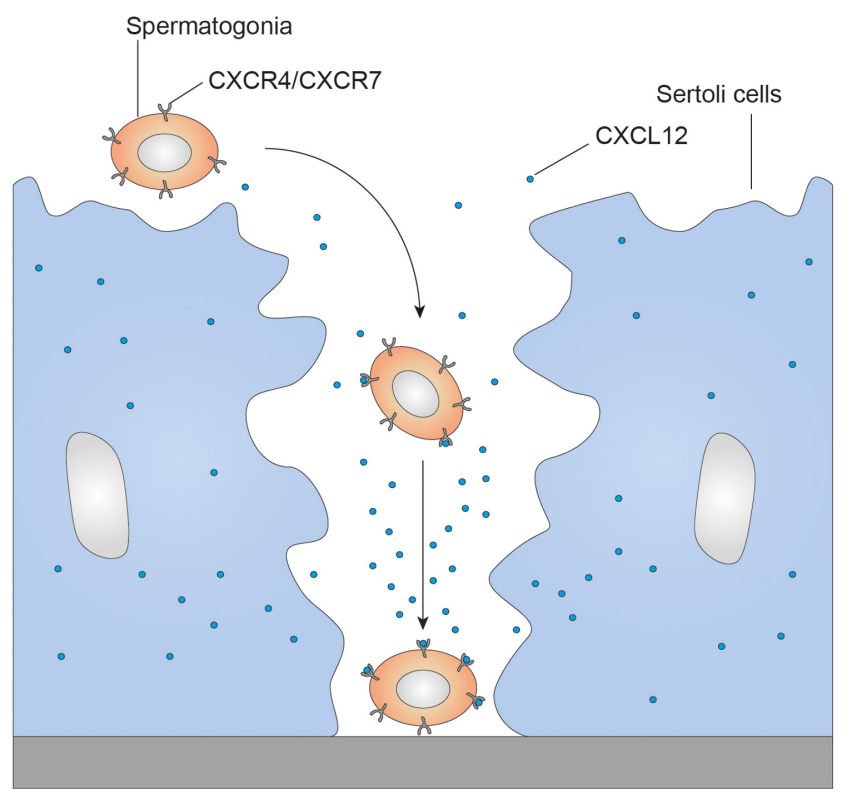

Figure 2 The role of the CXCL12 system in the homing process of SSCs into their niches. The process of SSC homing involves the formation of a CXCL12 gradient by Sertoli cells. SSCs then migrate along this gradient and home into their niches. 
its cytotoxic effect preferentially on spermatogonia, resulting in a successive loss also of the more differentiated germ cells (de Rooij \& Kramer 1968). Following treatment with busulfan at $38 \mathrm{mg} / \mathrm{kg}$, loss of LIN28a-positive spermatogonia was obvious on day 7 after treatment, whereas more differentiated germ cells (DDX4-positive) persisted until day 21. Importantly, on day 28 after treatment, repopulation of individual seminiferous tubules by LIN28-positive spermatogonia was observed (Westernströer et al. 2014). Although this sequence of events is corroborated by other studies, it is of note that the time of spermatogenic recovery is dependent on the treatment dose (Zohni et al. 2012). Nonetheless, studies using mice as animal model assessed the response of the testicular somatic cells in the first days following cytotoxic treatment and found comparable effects. In particular, Sertoli cells showed a rapid response with an upregulation of $G d n f$ following $15 \mathrm{mg} / \mathrm{kg}$ and $30 \mathrm{mg} / \mathrm{kg}$ of busulfan treatment (Zohni et al. 2012). In line with this, an independent study analysed 6 niche-associated factors and found comparable results with a significant upregulation of all 6 factors including Gdnf and Cxcl12 (Westernströer et al. 2014). As testicular tissue composition is still comparable to control tissues, these findings indeed suggest a prompt and temporary response of testicular somatic cells upon SSC depletion and tissue damage. Although protein data are largely lacking, a number of possible reasons for this findings have been proposed. In particular, increased levels of GDNF may enhance the self-renewal activity of remaining SSCs thereby enabling the repopulation of seminiferous tubules. Upregulation of CXCL12 may function as an enhanced homing signal guiding newly formed SSCs into vacant niches (Oatley et al 2007, Wu et al. 2011, Yang et al. 2013). This assumption is supported by the observation that out of 6 analysed niche-associated factors only Etv 5 and its downstream target $\mathrm{CxC} / 12$, showed significantly higher expression levels also on day 28 following treatment. At this time point, early spermatogenic repopulation was observed a process that might be supported by increased levels of CXCL12 (Westernströer et al. 2014). Using macaque as non-human primate model, effect of gonadotoxic insult on testicular somatic cells has also been evaluated. In particular, protein expression patterns of CXCL12 were analyzed in testicular tissues, following irradiation with 1 or $4 \mathrm{~Gy}$, respectively. Comparable to busulfan treatment, irradiation with these doses induces germ cell depletion but still allows for the recovery of spermatogenesis (1 Gy: 75-200 days; 4 Gy: 3-4 years) (van Alphen et al 1988, Jahnukainen et al. 2007). Using a xenografting model, the effect of this gonadotoxic insult on the stem cell niche of prepubertal macaques was assessed. Testicular tissues were retrieved 6.5 months following graft transplantation, and histological evaluation unveiled that spermatogonial re-population had progressed further in tissues treated with $1 \mathrm{~Gy}$ compared to those treated with 4 Gy. These tissues were further evaluated for the expression pattern of CXCL12 at protein level. Quantitative analyses revealed that a significantly higher number of seminiferous tubules showed expression of CXCL12 in all Sertoli cells in the 1 Gy compared to the 4 Gy group (Tröndle et al. 2017). These results demonstrate that the upregulation of CXCL12 in response to spermatogonial loss induced by gonadotoxic insult is evolutionarily conserved in mice and primates (Zohni et al. 2012, Westernströer et al. 2014) and suggests an involvement of the chemokine CXCL12 in spermatogonial repopulation. It also appears likely that CXCL12 may not only play a role in the stimulation of germ cell migration and homing but also stimulates spermatogonial proliferation.

\section{CXCL12 does not enhance germ cell proliferation in zebrafish, mice or human}

The process of germ cell migration is characterized by an increase of the PGC population by mitotic expansion. CXCL12 has therefore been proposed to act as an external signal supporting the proliferation of PGCs. However, data from zebrafish lacking Cxcl12 demonstrate that this chemokine is not required for PGC proliferation (Wei \& Liu 2014). In mice, insights were gained by evaluation of CXCR4-deficient embryos, which displayed a strikingly lower number of PGCs by day E11.5. However, comparative quantification of PGCs during the developmental stages from 10.5 to 12.5 revealed that $\mathrm{CXCL} 12 / \mathrm{CXCR} 4$ interaction was dispensable for PGC proliferation but required for germ cell survival (Ara et al. 2003).

It has been speculated that the interaction of CXCL12 with its receptor CXCR4 might also be crucial in the adult testis for SSC proliferation. In order to address a potential influence of CXCL12 on SSC proliferation mouse SSC cultures were treated in parallel approaches with recombinant CXCL12 at a concentration of $10 \mathrm{ng} / \mathrm{mL}$, with AMD3100 or a combination of both. Unexpectedly though, the numbers of SSCs were comparable in all treatment groups following 7 days of culture (Niu et al. 2016). Comparable results were obtained in an independent study. Following 6 days of culture, the numbers of germline stem cells were similar irrespective of whether CXCL12 or AMD3100 had been added to the culture medium (Kanatsu-Shinohara et al. 2012). These findings consistently show that there is no effect of the CXCL12/CXCR4 interaction on SSC proliferation. Although the influence of CXCL12 on SSC proliferation in primates has not been assessed directly, data are available for the human testicular germ cell tumourderived cell line TCam-2 (Gilbert et al. 2010, Mclver et al. 2013). As mentioned previously, and in accordance with data obtained for mouse spermatogonia, CXCL12 had no effect on the proliferation of TCam-2 cells in vitro (Gilbert et al. 2010, Mclver et al. 2013). 


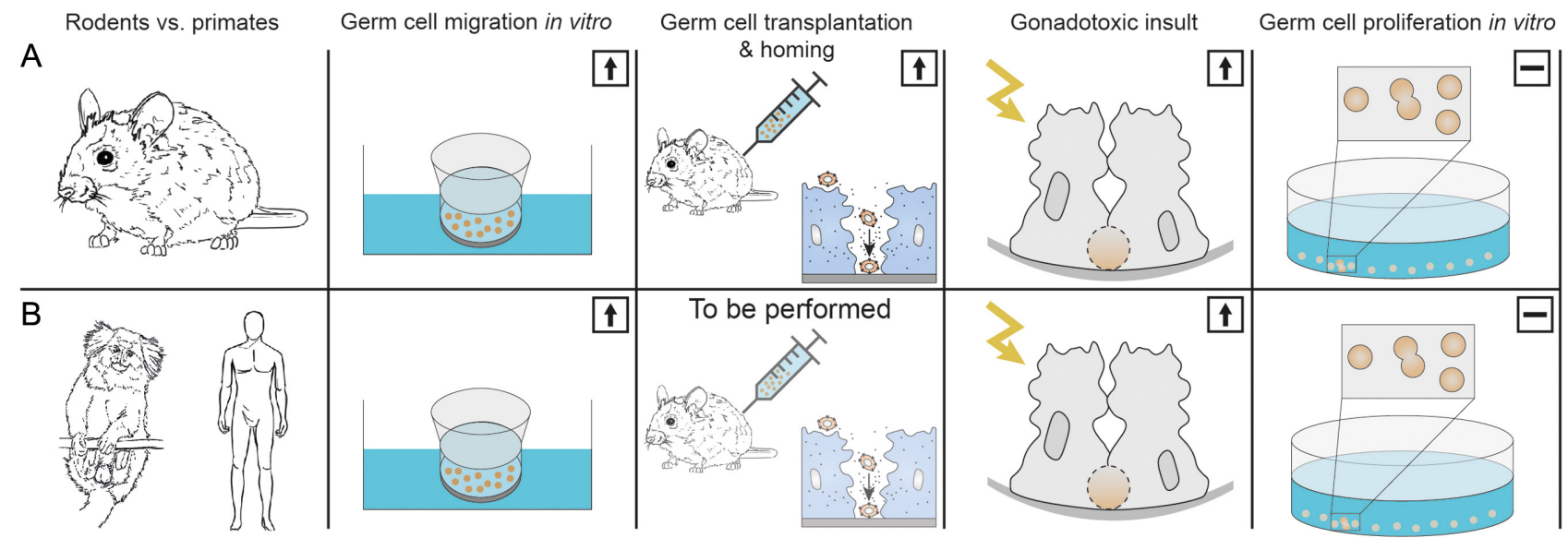

Figure 3 Functional analyses of CXCL12, CXCR4 and CXCR7 in rodents and primates including the human. (A) In mice, current data demonstrate that CXCL12 has an effect on germ cell migration in vitro and in vivo and in particular for homing of SSCs into their niches. Furthermore, analyses of murine testicular tissues following gonadotoxic insult (radiation or chemotherapy) and in particular in tissues showing repopulation of spermatogonia revealed increased expression levels of CXCL12. However, CXCl12 does not have an impact on germ cell proliferation. (B) For primate testicular tissues, analyses showed comparable results to rodent studies regarding germ cell migration and proliferation and an activation of the CXCL12 system following gonadotoxic insult. However, in primates, in vivo germ cell transplantation studies have not yet been performed. Positive effect of CXCL12 in the different processes is indicated by an arrow, whereas a line demonstrates the absence of an effect.

\section{Conclusion and future perspectives}

Available data clearly demonstrate that the function of CXCL12 interaction with its receptors CXCR4 and CXCR7 is essential for directed migration of PGCs in zebrafish and mice. Based on this evolutionary conservation, it is likely that the same is true also for primates, including the human. As access to human testicular tissues from early developmental stages is limited for ethical and legal reasons, expression pattern of CXCL12 and its receptors needs to be assessed during early developmental stages in primate animal model, to gain insight if this system is also regulating PGC migration. Moreover, more recent studies have demonstrated that the CXCL12 system remains functional also at later stages of germ cell development. In particular the homing process of mouse gonocytes into their germ cell niches is regulated by the CXCL12 system. But what is more, expression of CXCR4 and CXCR7 on the cell surface persists even in adult spermatogonia and facilitates their CXCL12-induced migration. For adult mouse SSCs, the process of SSChoming following germ cell transplantation has been demonstrated to be CXCL12 dependent. Evolutionarily highly conserved expression pattern of CXCL12 in Sertoli cells of mice, marmoset and human indicate that this chemokine is also an essential part of the adult SSC niche. For primates and humans, functional in vitro or in vivo data are not yet available (Fig. 3). As a first step, ability of primate or human SSCs to migrate towards a CXCL12 gradient can be tested using the Boyden chamber approach, provided that sufficient cell numbers can be obtained for subsequent analyses. For final functional proof, germ cell transplantation assays need to be performed. As germ cell transplantation assays were shown to be feasible also employing adult primate SSCs as well as the human TCam-2 cell line (Nettersheim et al. 2012, Langenstroth et al. 2014), transplantation into testicular tissues with artificially increased expression levels of CXCL12 would provide evidence on the regulatory mechanisms of SSC migration and homing in the primate species.

\section{Declaration of interest}

The authors declare that there is no conflict of interest that could be perceived as prejudicing the impartiality of this review.

\section{Funding}

This research did not receive any specific grant from any funding agency in the public, commercial or not-for-profit sector.

\section{References}

Aeckerle N, Eildermann K, Drummer C, Ehmcke J, Schweyer S, Lerchl A, Bergmann M, Kliesch S, Gromoll J, Schlatt S et al. 2012 The pluripotency factor LIN28 in monkey and human testes: a marker for spermatogonial stem cells? Molecular Human Reproduction 18 477-488. (https://doi. org/10.1093/molehr/gas025)

Aeckerle N, Drummer C, Debowski K, Viebahn C \& Behr R 2015 Primordial germ cell development in the marmoset monkey as revealed by pluripotency factor expression: suggestion of a novel model of embryonic germ cell translocation. Molecular Human Reproduction 21 66-80. (https://doi.org/10.1093/molehr/gau088)

Albert S, Ehmcke J, Wistuba J, Eildermann K, Behr R, Schlatt S \& Gromoll J 2010 Germ cell dynamics in the testis of the postnatal common marmoset monkey (Callithrix jacchus). Reproduction 140 733-742. (https://doi. org/10.1530/REP-10-0235) 
Ara T, Nakamura Y, Egawa T, Sugiyama T, Abe K, Kishimoto T, Matsui Y \& Nagasawa T 2003 Impaired colonization of the gonads by primordial germ cells in mice lacking a chemokine, stromal cell-derived factor-1 (SDF-1). PNAS $\mathbf{1 0 0}$ 5319-5323. (https://doi.org/10.1073/ pnas.0730719100)

Balabanian K, Lagane B, Infantino S, Chow KYC, Harriague J, Moepps B, Arenzana-Seisdedos F, Thelen M \& Bachelerie F 2005 The chemokine SDF-1/CXCL12 binds to and signals through the orphan receptor RDC1 in T lymphocytes. Journal of Biological Chemistry 280 35760-35766. (https://doi.org/10.1074/jbc.M508234200)

Boldajipour B, Mahabaleshwar H, Kardash E, Reichman-Fried M, Blaser H, Minina S, Wilson D, Xu Q \& Raz E 2008 Control of chemokine-guided cell migration by ligand sequestration. Cell 132 463-473. (https://doi. org/10.1016/j.cell.2007.12.034)

Brinster RL \& Zimmermannt JW 1994 Spermatogenesis following male germ-cell transplantation. Developmental Biology 91 11298-11302.

Burns JM, Summers BC, Wang Y, Melikian A, Berahovich R, Miao Z, Penfold MET, Sunshine MJ, Littman DR, Kuo CJ et al. 2006 A novel chemokine receptor for SDF-1 and I-TAC involved in cell survival, cell adhesion, and tumor development. Journal of Experimental Medicine 203 2201-2213. (https://doi.org/10.1084/jem.20052144)

Bussmann J \& Raz E 2015 Chemokine-guided cell migration and motility in zebrafish development. EMBO Journal 34 1309-1318. (https://doi. org/10.15252/embj.201490105)

Chen SR \& Liu YX 2015 Regulation of spermatogonial stem cell self-renewal and spermatocyte meiosis by Sertoli cell signaling. Reproduction 149 R159-R167. (https://doi.org/10.1530/REP-14-0481)

Chen S-R, Tang J-X, Cheng J-M, Li J, Jin C, Li X-Y, Deng S-L, Zhang Y, Wang X-X \& Liu Y-X 2015 Loss of Gata4 in Sertoli cells impairs the spermatogonial stem cell niche and causes germ cell exhaustion by attenuating chemokine signaling. Oncotarget 6 37012-37027. (https:// doi.org/10.18632/oncotarget.6115)

de Felici M 2013 Origin, migration, and proliferation of human primordial germ cells. In Oogenesis, pp 19-37. Eds G Coticchio, D Albertini \& L De Santis. London: Springer. (https://doi.org/10.1007/978-0-85729-8263_2)

de Rooij DG \& Kramer MF 1968 Spermatogonial stem cell renewal in the rat, mouse and golden hamster. A study with the alkylating agent myleran. Zeitschrift Fur Zellforschung und Mikroskopische Anatomie 92 400-405. (https://doi.org/10.1007/BF00455597)

de Vries ME, Kelvin AA, Xu L, Ran L, Robinson J \& Kelvin DJ 2006 Defining the origins and evolution of the chemokine/chemokine receptor system. Journal of Immunology 176 401-415. (https://doi.org/10.4049/ jimmunol.176.1.401)

Doitsidou M, Reichman-Fried M, Stebler J, Köprunner M, Dörries J, Meyer D, Esguerra CV, Leung T \& Raz E 2002 Guidance of primordial germ cell migration by the chemokine SDF-1. Cell 111 647-659. (https:// doi.org/10.1016/S0092-8674(02)01135-2)

Drumond AL, Meistrich ML \& Chiarini-Garcia H 2011 Spermatogonial morphology and kinetics during testis development in mice: a highresolution light microscopy approach. Reproduction 142 145-155. (https://doi.org/10.1530/REP-10-0431)

Ehmcke J, Wistuba J \& Schlatt S 2006 Spermatogonial stem cells: questions, models and perspectives. Human Reproduction Update 12 275-282. (https://doi.org/10.1093/humupd/dmk001)

Gallagher SJ, Kofman AE, Huszar JM, Dannenberg JH, DePinho RA, Braun RE \& Payne CJ 2013 Distinct requirements for Sin3a in perinatal male gonocytes and differentiating spermatogonia. Developmental Biology 373 83-94. (https://doi.org/10.1016/j.ydbio.2012.10.009)

Gerrits H, Van Ingen Schenau DS, Bakker NEC, Van Disseldorp AJM, Strik A, Hermens LS, Koenen TB, Krajnc-Franken MAM \& Gossen JA 2008 Early postnatal lethality and cardiovascular defects in CXCR7deficient mice. Genesis 46 235-245. (https://doi.org/10.1002/dvg.20387)

Gilbert D, Chandler I, McIntyre A, Goddard N, Gabe R, Huddart R \& Shipley J 2010 Clinical and biological significance of CXCL12 and CXCR4 expression in adult testes and germ cell tumours of adults and adolescents. Journal of Pathology 217 94-102. (https://doi.org/10.1002/ path.2436)

Goriely A, McVean GAT, Röjmyr M, Ingemarsson B \& Wilkie AOM 2003 Evidence for selective advantage of pathogenic FGFR2 mutations in the male germ line. Science 301 643-646. (https://doi.org/10.1126/ science.1085710)
Habasque C, Aubry F, Jégou B \& Samson M 2002 Study of the HIV-1 receptors $\mathrm{CD} 4, \mathrm{CXCR} 4, \mathrm{CCR} 5$ and $\mathrm{CCR} 3$ in the human and rat testis. Molecular Human Reproduction 8 419-425. (https://doi.org/10.1093/ molehr/8.5.419)

Hess RA, Cooke PS, Hofmann M-C \& Murphy KM 2006 Mechanistic insights into the regulation of the spermatogonial stem cell niche. Cell Cycle 5 1164-1170. (https://doi.org/10.4161/cc.5.11.2775)

Hofmann M-C 2008 Gdnf signaling pathways within the mammalian spermatogonial stem cell niche. Molecular and Cellular Endocrinology 288 95-103. (https://doi.org/10.1016/j.mce.2008.04.012)

Honecker F, Stoop H, de Krijger RR, Lau YFC, Bokemeyer C \& Looijenga LHJ 2004 Pathobiological implications of the expression of markers of testicular carcinoma in situ by fetal germ cells. Journal of Pathology 203 849-857. (https://doi.org/10.1002/path.1587)

Huff DS, Fenig DM, Canning DA, Carr MC, Zderic SA \& Snyder HM 2001 Abnormal germ cell development in cryptorchidism. Hormone Research 55 11-17. (https://doi.org/10.1159/000049957)

Irie N, Weinberger L, Tang WWC, Kobayashi T, Viukov S, Manor YS, Dietmann S, Hanna JH \& Surani MA 2015 SOX17 is a critical specifier of human primordial germ cell fate. Cell 160 253-268. (https://doi. org/10.1016/j.cell.2014.12.013)

Jahnukainen K, Ehmcke J, Nurmio M \& Schlatt S 2007 Irradiation causes acute and long-term spermatogonial depletion in cultured and xenotransplanted testicular tissue from juvenile nonhuman primates. Endocrinology 148 5541-5548. (https://doi.org/10.1210/ en.2007-0809)

Kanatsu-Shinohara M, Inoue K, Takashima S, Takehashi M, Ogonuki N, Morimoto H, Nagasawa T, Ogura A \& Shinohara T 2012 Reconstitution of mouse spermatogonial stem cell niches in culture. Cell Stem Cell $1 \mathbf{1}$ 567-578. (https://doi.org/10.1016/j.stem.2012.06.011)

Knaut H, Werz C, Geisler R, The Tübingen 2000 Screen Consortium and Nüsslein-Volhard C 2003 A zebrafish homologue of the chemokine receptor $\mathrm{Cxcr4}$ is a germ-cell guidance receptor. Nature 421 279-282. (https://doi.org/10.1038/nature01338)

Langenstroth D, Kossack N, Westernströer B, Wistuba J, Behr R, Gromoll J \& Schlatt S 2014 Separation of somatic and germ cells is required to establish primate spermatogonial cultures. Human Reproduction 29 2018-2031. (https://doi.org/10.1093/humrep/deu157)

Li L-H, Donald JM \& Golub MS 2005 Review on testicular development, structure, function, and regulation in common marmoset. Birth Defects Research Part B: Developmental and Reproductive Toxicology 74 450-469. (https://doi.org/10.1002/bdrb.20057)

Ma Q, Jones D, Borghesani PR, Segal RA, Nagasawa T, Kishimoto T, Bronson RT \& Springer TA 1998 Impaired B-lymphopoiesis, myelopoiesis, and derailed cerebellar neuron migration in CXCR4- and SDF-1-deficient mice. PNAS 95 9448-9453. (https://doi.org/10.1073/ pnas.95.16.9448)

Mahabaleshwar H, Boldajipour B \& Raz E 2008 Killing the messenger: the role of CXCR7 in regulating primordial germ cell migration. Cell Adhesion and Migration 2 69-70. (https://doi.org/10.4161/cam.2.2.6027)

McIver SC, Loveland KL, Roman SD, Nixon B, Kitazawa R \& McLaughlin EA 2013 The chemokine CXCL12 and its receptor CXCR4 are implicated in human seminoma metastasis. Andrology 1 517-529. (https://doi. org/10.1111/j.2047-2927.2013.00081.x)

Meng X, Lindahl M, Hyvönen ME, Parvinen M, de Rooij DG, Hess MW, Raatikainen-Ahokas A, Sainio K, Rauvala H, Lakso M et al. 2000 Regulation of cell fate decision of undifferentiated spermatogonia by GDNF. Science 287 1489-1493. (https://doi.org/10.1126/ science.287.5457.1489)

Mitchell RT, Cowan G, Morris KD, Anderson RA, Fraser HM, Mckenzie KJ, Wallace WHB, Kelnar CJH, Saunders PTK \& Sharpe RM 2008 Germ cell differentiation in the marmoset (Callithrix jacchus) during fetal and neonatal life closely parallels that in the human. Human Reproduction 23 2755-2765. (https://doi.org/10.1093/humrep/den295)

Molyneaux KA, Zinszner H, Kunwar PS, Schaible K, Stebler J, Sunshine MJ, O'Brien W, Raz E, Littman D, Wylie C et al. 2003 The chemokine SDF1/ CXCL12 and its receptor CXCR4 regulate mouse germ cell migration and survival. Development 130 4279-4286. (https://doi.org/10.1242/ dev.00640)

Mullaney BP \& Skinner MK 1992 Basic Fibroblast growth factor (bFGF) gene expression and protein production during pubertal development of the seminiferous tubule: follicle-stimulating hormone-induced Sertoli 
cell bFGF expression. Endocrinology 131 1928-2934. (https://doi. org/10.1210/endo.131.6.1446630)

Nagano R, Tabata S, Nakanishi Y, Ohsako S, Kurohmaru M \& Hayashi Y 2000 Reproliferation and relocation of mouse male germ cells (gonocytes) during prespermatogenesis. Anatomical Record 258 210-220. (https:// doi.org/10.1002/(SICI)1097-0185(20000201)258:2<210::AIDAR10>3.0.CO;2-X)

Nettersheim D, Westernströer B, Haas N, Leinhaas A, Brüstle O, Schlatt S \& Schorle H 2012 Establishment of a versatile seminoma model indicates cellular plasticity of germ cell tumor cells. Genes, Chromosomes and Cancer 51 717-726. (https://doi.org/10.1002/gcc.21958)

Niu Z, Goodyear SM, Avarbock MR \& Brinster RL 2016 Chemokine (C-X-C) ligand 12 facilitates trafficking of donor spermatogonial stem cells. Stem Cells International 2016 5796305. (https://doi. org/10.1155/2016/5796305)

O'Bryan MK, Grealy A, Stahl PJ, Schlegel PN, McLachlan RI \& Jamsai D 2012 Genetic variants in the ETV5 gene in fertile and infertile men with nonobstructive azoospermia associated with Sertoli cell-only syndrome. Fertility and Sterility 98 827-835. (https://doi.org/10.1016/j. fertnstert.2012.06.013)

Oatley JM, Avarbock MR, Telaranta AI, Fearon DT \& Brinster RL 2006 Identifying genes important for spermatogonial stem cell self-renewal and survival. PNAS 103 9524-9529. (https://doi.org/10.1073/ pnas.0603332103)

Oatley JM, Avarbock MR \& Brinster RL 2007 Glial cell line-derived neurotrophic factor regulation of genes essential for self-renewal of mouse spermatogonial stem cells is dependent on Src family kinase signaling. Journal of Biological Chemistry 282 25842-25851. (https:// doi.org/10.1074/jbc.M703474200)

Payne CJ, Gallagher SJ, Foreman O, Dannenberg J-H, De Pinho RA \& Braun RE 2010 Sin3a is required by sertoli cells to establish a niche for undifferentiated spermatogonia, germ cell tumors, and spermatid elongation. Stem cells 28 1424-1434. (https://doi.org/10.1002/stem.464)

Raz E 2004 Guidance of primordial germ cell migration. Current Opinion in Cell Biology 16 169-173. (https://doi.org/10.1016/j.ceb.2004.01.004)

Raz E \& Mahabaleshwar H 2009 Chemokine signaling in embryonic cell migration: a fisheye view. Development 136 1223-1229. (https://doi. org/10.1242/dev.022418)

Richardson BE \& Lehmann R 2010 Mechanisms guiding primordial germ cell migration: strategies from different organisms. Nature Reviews Molecular Cell Biology 11 37-49. (https://doi.org/10.1038/nrm2815)

Saitou M \& Yamaji M 2012 Primordial germ cells in mice. Cold Spring Harbor Laboratory Press 11 a008375. (https://doi.org/10.1101/ cshperspect.a008375)

Sette C, Dolci S, Geremia R \& Rossi P 2000 The role of stem cell factor or and of alternative c-kit gene products in the establishment, maintenance and function of germ cells. The International Journal of Developmental Biology 44 599-608.

Sierro F, Biben C, Martinez-Munoz L, Mellado M, Ransohoff RM, Li M, Woehl B, Leung H, Groom J, Batten M et al. 2007 Disrupted cardiac development but normal hematopoiesis in mice deficient in the second CXCL12/SDF-1 receptor, CXCR7. PNAS 104 14759-14764. (https://doi. org/10.1073/pnas.0702229104)

Spradling A, Drummond-Barbosa D \& Kai T 2001 Stem cells find their niche. Nature 414 98-104. (https://doi.org/10.1038/35102160)

Tang WWC, Dietmann S, Irie N, Leitch HG, Floros VI, Bradshaw CR, Hackett JA, Chinnery PF \& Surani MA 2015 A unique gene regulatory network resets the human germline epigenome for development. Cell 161 1453-1467. (https://doi.org/10.1016/j.cell.2015.04.053)
Tang WWC, Kobayashi T, Irie N, Dietmann S \& Surani MA 2016 Specification and epigenetic programming of the human germ line. Nature Reviews Genetics 17 585-600. (https://doi.org/10.1038/ nrg.2016.88)

Tröndle I, Westernströer B, Wistuba J, Terwort N, Schlatt S \& Neuhaus N 2017 Irradiation affects germ and somatic cells in prepubertal monkey testis xenografts. Molecular Human Reproduction 23 141-154. (https:// doi.org/10.1093/molehr/gax003)

van Alphen MM, van de Kant HJ \& de Rooij DG 1988 Depletion of the spermatogonia from the seminiferous epithelium of the rhesus monkey after X irradiation. Radiation Research 113 473-486. (https://doi. org/10.2307/3577244)

van der Kooy D, van der Kooy D, Weiss S \& Weiss S 2000 Why stem cells? Science 287 1439-1441. (https://doi.org/10.1126/ science.287.5457.1439)

Wei KH \& Liu IH 2014 Heparan sulfate glycosaminoglycans modulate migration and survival in zebrafish primordial germ cells. Theriogenology 81 1275-1285. (https://doi.org/10.1016/j.theriogenology.2014.02.009)

Westernströer B, Terwort N, Ehmcke J, Wistuba J, Schlatt S \& Neuhaus N 2014 Profiling of Cxcl12 receptors, Cxcr4 and Cxcr7 in murine testis development and a spermatogenic depletion model indicates a role for Cxcr7 in controlling Cxcl12 activity. PLoS ONE 9 1-18. (https://doi. org/10.1371/journal.pone.0112598)

Westernströer B, Langenstroth D, Kliesch S, Troppmann B, Redmann K, Macdonald J, Mitchell R, Wistuba J, Schlatt S \& Neuhaus N 2015 Developmental expression patterns of chemokines CXCL11, CXCL12 and their receptor CXCR7 in testes of common marmoset and human. Cell and Tissue Research 361 885-898. (https://doi.org/10.1007/s00441015-2164-1)

Wu X, Goodyear SM, Tobias JW, Avarbock MR \& Brinster RL 2011 Spermatogonial stem cell self-renewal requires ETV5-mediated downstream activation of Brachyury in mice. Biology of Reproduction 85 1114-1123. (https://doi.org/10.1095/biolreprod.111.091793)

Yang Q-E, Kim D, Kaucher A, Oatley MJ \& Oatley JM 2013 CXCL12-CXCR4 signaling is required for the maintenance of mouse spermatogonial stem cells. Journal of Cell Science 126 1009-1020. (https://doi.org/10.1242/ jcs.119826)

Yoon KA, Chae YM \& Cho JY 2009 FGF2 stimulates SDF-1 expression through the Erm transcription factor in sertoli cells. Journal of Cellular Physiology 220 245-256. (https://doi.org/10.1002/jcp.21759)

Zlotnik A, Yoshie O \& Nomiyama H 2006 The chemokine and chemokine receptor superfamilies and their molecular evolution. Genome Biology 7 243. (https://doi.org/10.1186/gb-2006-7-12-243)

Zohni K, Zhang X, Tan SL, Chan P \& Nagano MC 2012 The efficiency of male fertility restoration is dependent on the recovery kinetics of spermatogonial stem cells after cytotoxic treatment with busulfan in mice. Human Reproduction 27 44-53. (https://doi.org/10.1093/humrep/der357)

Zou Y-R, Kottmann AH, Kuroda M, Taniuchi I \& Littman DR 1998 Function of the chemokine receptor CXCR4 in haematopoiesis and in cerebellar development. Nature 393 595-599. (https://doi.org/10.1038/31269)

Received 12 October 2017

First decision 1 December 2017

Revised manuscript received 6 January 2018

Accepted 1 February 2018 